ISSN 2075-471X

www.mdpi.com/journal/laws/

Article

\title{
Post-Release Success among Paroled Lifers
}

\section{Marieke Liem ${ }^{1, *}$ and Jennifer Garcin ${ }^{2}$}

1 Kennedy School of Government, Harvard University, 79 JFK Street, Cambridge, MA 02138, USA

2 College of Social Sciences and Humanities, Northeastern University, 360 Huntington Ave., Boston, MA 02115, USA; E-Mail: jengarcin@gmail.com

* Author to whom correspondence should be addressed; E-Mail: Marieke_Liem@hks.harvard.edu

External Editor: Robert Johnson

Received: 26 August 2014; in revised form: 22 November 2014 / Accepted: 24 November 2014 / Published: 15 December 2014

\begin{abstract}
Previous research suggests that social relations, in particular the forming of family ties and employment (social factors), self-efficacy (personal factors), and therapeutic interventions (institutional factors) constitute main contributors in post-release success. These studies, however, have largely been based on general delinquents serving relatively short prison terms. This study aims to shed light on the influence of social, personal, and institutional factors on post-release success versus failure among paroled lifers. We conducted in-depth life-history interviews with 64 individuals who had served a life sentence, who were either re-incarcerated for another crime or parole violation, or were currently out on parole. The role of social factors in desistance among long-term incarcerated offenders was minimal. Rather, self-efficacy appeared to be a key element in post-release success. These findings suggest that research based on short-term incarcerated offenders cannot be directly translated to long-term incarcerated offenders. This group does not experience the same traditional turning points, such as establishing family ties and employment. Accordingly, long-term prisoners may go through a different process post-release that determines their success versus failure compared to general delinquents who serve shorter sentences.
\end{abstract}

Keywords: desistance; redemption; effects of imprisonment; violent offenders; life course; agency; self-efficacy; recidivism 


\section{Introduction}

Nearly 95 percent of the 1.6 million US prison inmates will eventually be released and return to their communities. In 2010 alone, this amounted to 708,677 individuals [1]. An even larger number of inmates are to be released annually in future years, as more inmates complete extended prison sentences [2]. Most prisoners released today serve relatively short prison terms of approximately two years [1]. We know very little, however, about how the roughly 7000 long-term prisoners, such as those incarcerated for homicide and other violent crimes [3], fare after release. One of the significant challenges the justice system faces when releasing this particular group from prison is the inability to predict their probability of desistance. These long-term prisoners constitute a unique population. On average, men are released from state prison at 35 years old [4]. However, by the time lifers face the possibility of parole, they are much older, and hence, are likely to face different problems and to have distinctive needs from those released in their thirties [5]. The goal of this study is to develop a better understanding of the factors that affect post-release success and post-release failure in paroled lifers.

\subsection{Background}

Previous qualitative research on desistance emphasizes the role of identity change, or a cognitive transformation from a criminal career to a conventional life, as key to desistance from criminal behavior [6,7]. Such cognitive transformations are typically preceded by one or more turning points: Life events that trigger a change of an "old", criminal identity to a new, pro-social self. Previous, mainly quantitative studies, have pointed to various factors including the role of interpersonal relationships [8,9], employment [9-12], or treatment programs [13] as causal agents in such change. These factors can roughly be clustered into social, institutional, and personal factors.

First, with the term "social factors" we refer to intimate partner relationships, the role as a parent, pre-existing family ties, and social relationships associated with steady employment. Second, by focusing on institutional factors we capture the notion that institutions, particularly prison programs and post-prison programs, may contribute to the desistance process. Third, with personal factors we refer to one's own sense of mastery and competence, the self-perceived capacity to use good judgment and exercise agency.

Previous studies on the role each of these clusters play in the desistance process have mainly focused on general offenders, those who have been incarcerated for a relatively short period of time. So far, we do not know to what extent these findings are applicable to the desistance process of individuals who have been removed from society for a long period of time. This study advances existing knowledge on desistance by addressing this gap in the literature. Unlike previous studies on desistance among ex-offenders, which were mainly based on general delinquents who served relatively short prison terms, the current study explores reasons for desistance among individuals who have served a life sentence. The goal of this study is to develop a better understanding of how the role of social, institutional, and personal factors may affect desistance in lifers released from prison. Note that we use the term "lifers" throughout this article to refer to individuals who have received and served a life sentence with the possibility of parole (with the exception of four interviewees who were exonerated and two who "wrapped up"-completed the entirety of their sentence in prison, and were 
therefore released without any parole stipulation. Because we were interested in examining the factors that determined success or failure post-release, we did not include lifers who were serving life sentences without the possibility of parole (LWOP).

\subsection{Social Factors}

From previous research on the development of crime among general delinquents, particularly work by Rob Sampson and John Laub [14,15], desistance from crime in adulthood can be meaningfully understood by changes in informal social control. Their age-graded theory of social control predicts that criminal behavior changes as important life events change-the stronger the ties to family and work, the less the criminal behavior. Their work emphasizes how desistance is related to social factors; they argue that the positive influence of a spouse or employer creates a social dynamic that produces informal forms of social control. Prior research has shown that assuming traditional roles within a family, such as parent or spouse, can benefit in the reentry transition process as it aids in the development of pro-social identities [12,16,17]. Recently, Cid and Martí [8] emphasized that family support should be considered not as a "turning point", but as a "returning point" in the desistance process. They found that pre-existing social bonds, such as family ties, were fundamental in moving away from criminal behavior. In this dynamic, offenders desist from criminal behavior, because they feel a moral duty to change as compensation for family support received during incarceration. Similar processes are at work when it comes to the role of employment in the desistance process; the employed are likely to experience close and frequent contact with conventional others, and the informal social controls of the workplace encourage conformity $[11,16]$.

Marriage, parenthood, family ties, and employment are thought to constitute "(re)turning points": Social factors that facilitate the alteration of criminal trajectories, putting ex-offenders on a path towards desistance $[11,14,18]$. Again, these findings, however, are largely based on general delinquents. It is therefore not known to what extent these social factors also play a role in the desistance process of lifers. Our study aims to bridge this gap.

\subsection{Institutional Factors}

A second cluster of factors associated with desistance post-release focuses on the role of prison and post-incarceration programming. Several meta-analyses on the effects of correctional treatment suggest that multimodel treatment (targeting a number of criminogenic needs) in general [19], and behavioral/social programs specifically [20], are a key factor for reducing offender recidivism. Following Wright et al. [21], in order to assess the role of institutions in the desistance process, we do not examine the mere presence of correctional treatment programs and post-incarceration institutions, but rather the extent to which the interviewees attribute their success post-release to the programs they participated in during and after imprisonment.

\subsection{Personal Factors}

The most common personal factor in the debate surrounding desistance is the role of self-efficacy, the self-perception or belief that one has the capacity to manage situations or succeed at various tasks [22]. 
These include social tasks, such as making friends, resolving interpersonal conflict, giving and receiving help, and being assertive. Self-efficacy also includes developmental tasks, such as preparing for a career, obtaining a job, completing an education, and finding a suitable companion. Self-efficacy speaks to one's sense of mastery and competence, the self-perceived capacity to use good judgment and exercise agency [23]. In his qualitative work on desistance in criminal behavior, Maruna (2001) distinguishes between "Pawns" and "Origins" ([7], p. 76) — "Pawns" are those who believe that life outcomes are largely dependent on circumstances and chance events; this group is less likely to desist. "Origins", on the other hand, reflect high self-efficacy, and believe that they are masters of their own fates and share a "language of agency" or self-initiative; their sense of control over their destiny makes them more likely to succeed post-release than their non-agentic counterparts. Both Maruna's work [7] and other studies that focus on cognitive transformations and identity change (e.g., [6]), have mainly focused on general delinquents serving relatively short periods of time in prison. Again, it is not known to what extent similar dynamics of self-efficacy are at work among those who served a long prison sentence. Therefore, we focus our inquiry on the extent to which self-efficacy plays a role in the desistance process.

Our focus on lifers is particularly important given the long prison terms these individuals serve. Most lifers are sentenced in their twenties or early thirties [5], a time when most conventional transition points take place (finding a suitable partner, becoming a parent, establishing a career). An accumulating body of research [24-27] suggests that punishment postpones transitions to work and family formation. Even though it has been suggested that troubled transitions are especially common for those experiencing harsh punishment $[12,26]$ — such as those serving a long prison sentence —we do not know to what extent lifers are able to "catch up" (i.e., make these life-course transitions after incarceration, at an older age), or to what extent they "missed the boat" (i.e., incarcerated at the age at which these life events could have acted as possible turning points).

\subsection{This Study}

In this study, we seek to understand the influence of social, personal, and institutional factors on post-release success. Prior research suggests that all are needed for a successful desistance process [8,28]. The goal of this study is to develop a better understanding of how the role of these factors may affect post-release success in lifers released from prison. To this end, we offer the following research questions:

(1) What types of factors (social, institutional, and personal) are most prevalent in lifers' attributions to success post-release?

(2) How do lifers who were successful in staying out differ from lifers who are re-incarcerated in how they attribute success to these various factors?

(3) How do these results indicate how lifers may differ from short-term offenders?

We will address the first two research questions in the results, and reflect on the third question in the discussion. This study is unique in that it relies on narratives of both released lifers who are out on parole, as well as re-incarcerated lifers who were unsuccessful in staying out on parole. We opted for a qualitative approach, as analyses at the macro-level ignore many individual circumstances that are important in explaining desistance. By interviewing two groups of life-sentenced individuals - those 
who were successful in staying out of prison and those who were unsuccessful in their reentry process, and had been re-incarcerated - we overcome the limitation of other qualitative studies on desistance that typically rely on desistance narratives of individuals who have not yet been released (e.g., $[8,12])$. In contrast to these previous studies, we are able to assess the relationship between narratives of desistance and actual desistance. This study is the first of its kind to combine social, institutional, and personal factors in assessing the desistance process, rather than focusing on just one aspect of this three-fold model.

\section{Methodology}

Following prior research on desistance, we used narrative interviews to identify how interviewees constructed their narratives and evaluated their lives before, during, and after incarceration [7,8]. Second, by making use of a life-history calendar [14], we used the interviews to obtain information on the interviewees' life events, as well as determining the context in which these events took place. This dual approach allowed us to analyze both objective and subjective factors related to the formation of the narratives. When possible, we were also able to triangulate reported life events through corroboration with program and prison staff, family members, attorneys, and newspaper articles.

\subsection{Design}

This study is part of a larger research project on the influence of life events and imprisonment on recidivism among male and female lifers [29-32]. In this study, however, we focus exclusively on male lifers. Individuals were eligible for inclusion if: (a) they were convicted of a homicide, and received a life sentence with the possibility of parole in the Boston metropolitan area; (b) they had served and completed their sentence for this offense over the past 15 years; (c) they were released or paroled following their sentence; and (d) they were either currently re-incarcerated or were currently out on parole. To reiterate, in this study, we sought to determine what caused post-release success versus failure among released lifers. We considered "success" as staying out on parole, and "failure" as returning to prison.

\subsubsection{Non-Incarcerated Lifers}

We recruited non-incarcerated lifers by contacting local organizations that provide services for ex-offenders, ranging from legal services (attorneys) to counseling and assistance in housing and education. We gave these organizations a letter to present to the individuals who met the inclusion criteria, and were currently not incarcerated. Upon the individual's consent, we informed the participants about the study and gave an opportunity to opt in. Interviews typically took place at a participant's attorney's office or at one of the local organizations for ex-offenders. We interviewed a total of 28 lifers who had been out of prison a substantial number of years prior to the interview in order to provide evidence that the non-incarcerated lifers were, for the most part, desisting. Of this group, only two participants were released less than two years prior to the interview. Time spent out of prison ranged from three months to 23 years. The majority of interviewees had been released over 10 years prior to the interview. 


\subsubsection{Re-Incarcerated Lifers}

The Massachusetts Department of Correction selected individuals who met the above described inclusion criteria and were currently re-incarcerated in a Massachusetts Correctional Institution. After identifying the individuals that were qualified, corrections program officers (CPOs) at each facility presented a letter to the individuals, on our behalf, inviting them to participate in the interview. We interviewed a total of 36 re-incarcerated lifers in minimum, medium, and maximum-security prisons throughout Massachusetts.

\subsection{Interview Procedure}

All individuals were given the opportunity to ask questions about the study and their participation. All gave informed consent to participate prior to the interview, on the basis that their disclosed material would be made anonymous and unidentifiable. After the interview, the participants were de-briefed. Findings were shared where this was requested. The interviews with lifers on parole typically took place at one of the legal or counseling organizations, throughout a period of almost two years (November 2011-August 2013). Most research participants were interviewed once, in two cases there was a follow-up interview, and 10 individuals were contacted at a later stage for follow-up questions by phone. In-person interviews with re-incarcerated individuals took place over the course of 10 months (November 2012-August 2013). All interviews were one to six hours long, depending on the participant's responses.

We conducted in-depth, one-on-one, semi-structured life history interviews. The questions were developed to obtain a thorough description of the role of social, personal, and institutional factors on the interviewee's desistance process. The majority of the questions were open-ended (e.g., "Could you describe some of the challenges you initially faced after being released?"). Interviews with non-incarcerated individuals were audio-recorded and transcribed ad verbatim. As audio recording was prohibited inside prison facilities, the principal investigator (ML) conducted interviews with incarcerated individuals, while the research assistant (JG) took detailed notes that were immediately transcribed after the interview.

\subsection{Participants}

Interviewees were predominately White (See Table 1; 45\%) or Black (43\%), and approximately one-tenth were Hispanic or identified with another race. Interviewees' ages at the time of the interview ranged from 37 to 75 . Interviewees in both the re-incarcerated and the non-incarcerated group committed the homicide ${ }^{1}$ in their teens or twenties, between the late 1960 s and early 1990s. The time spent in prison for the homicide was on average 21 years, ranging from 6 to 40 years. Several individuals had served time-usually a couple of months to several years-before committing the

1 The majority of the interviewees were convicted for second-degree murder or (in)voluntary manslaughter. In Massachusetts, individuals serving a life sentence for first-degree murder are not eligible for parole and hence, have not been included in our study. Second-degree murder refers to homicide with malicious intent but without premeditation or extreme cruelty. Voluntary manslaughter includes willful homicide with provocation or from excessive force, while involuntary manslaughter refers to non-willful homicide resulting from negligence. 
homicide. At the time of the interviews, the large majority of interviewees $(\mathrm{N}=58 ; 91 \%)$ were on lifetime parole. It should be noted that of the non-incarcerated interviewees, four had their cases overturned, and two "wrapped up" (completed the entirety of their sentence in prison, and were therefore released without any parole stipulation).

Table 1. Demographic characteristics of interviewed lifers $(\mathrm{N}=68)$.

\begin{tabular}{|c|c|c|c|c|c|c|}
\hline \multirow[b]{2}{*}{ Demographic characteristics } & \multicolumn{2}{|c|}{$\begin{array}{c}\text { Non-incarcerated } \\
\text { interviewees } \\
(\mathbf{N}=\mathbf{2 8}) \\
\end{array}$} & \multicolumn{2}{|c|}{$\begin{array}{c}\text { Re-incarcerated } \\
\text { interviewees } \\
(\mathrm{N}=\mathbf{3 6}) \\
\end{array}$} & \multicolumn{2}{|c|}{$\begin{array}{c}\text { Total } \\
(\mathbf{N}=64) \\
\end{array}$} \\
\hline & $\mathrm{N}$ & $\%$ & $\mathrm{~N}$ & $\%$ & $\mathrm{~N}$ & $\%$ \\
\hline Age at offense & \multicolumn{2}{|c|}{$25.6 \pm 8.8$} & \multicolumn{2}{|c|}{$19.9 \pm 3.5$} & \multicolumn{2}{|c|}{$22.3 \pm 6.9$} \\
\hline Age at time of interview & \multicolumn{2}{|c|}{$55.7 \pm 9.8$} & \multicolumn{2}{|c|}{$53.3 \pm 8.7$} & \multicolumn{2}{|c|}{$54.4 \pm 9.2$} \\
\hline \multicolumn{7}{|l|}{ Race } \\
\hline White & 12 & 43 & 17 & 47 & 29 & 45 \\
\hline Black & 12 & 43 & 15 & 42 & 27 & 42 \\
\hline Latino & 3 & 11 & 3 & 8 & 6 & 9 \\
\hline Other & 1 & 4 & 1 & 3 & 2 & 3 \\
\hline \multicolumn{7}{|l|}{ Life sentence characteristics } \\
\hline \multicolumn{7}{|c|}{ Total years incarcerated for homicide } \\
\hline$\leq 15$ years & 10 & 36 & 5 & 14 & 15 & 23 \\
\hline $16-25$ years & 13 & 47 & 20 & 56 & 33 & 52 \\
\hline$\geq 26$ years & 5 & 18 & 11 & 31 & 16 & 25 \\
\hline Average sentence length & \multicolumn{2}{|c|}{$19.1 \pm 7.6$} & \multicolumn{2}{|c|}{$21.9 \pm 6.3$} & \multicolumn{2}{|c|}{$20.7 \pm 7.0$} \\
\hline \multicolumn{7}{|l|}{ Age at time of first parole ${ }^{2}$} \\
\hline$\leq 35$ & 4 & 15 & 8 & 22 & 12 & 19 \\
\hline $36-45$ & 12 & 44 & 17 & 47 & 29 & 46 \\
\hline$\geq 51$ & 11 & 41 & 11 & 31 & 22 & 35 \\
\hline Average age at parole & \multicolumn{2}{|c|}{$44.7 \pm 11.9$} & \multicolumn{2}{|c|}{$41.8 \pm 6.9$} & \multicolumn{2}{|c|}{$43.0 \pm 9.4$} \\
\hline
\end{tabular}

Even though it has been argued that lifers constitute a mere legal group, rather than a sociological group [33], the commonalities between individuals were striking. On the outset, these similarities include socio-demographic characteristics, and life sentence characteristics. They are a heterogeneous, though collective, group of individuals, whose histories leading up to the homicide were remarkably similar. Their demographic characteristics (see Table 1) also suggest that this selected group of interviewees have much in common with first-degree lifers [34] who, because of the nature of their sentence, are not eligible for parole.

The interviewed lifers differ drastically, however, from the overall released adult prisoner population in Massachusetts in terms of their age at parole [35]. Statewide, on average, inmates serve about six years, while the lifers in this study served more than 20 years and therefore were much older at first parole.

The majority reported an extensive criminal history before the homicide, being involved in activities, such as property crimes, drug dealing, and (armed) robberies. Most participants in this group resided in (impoverished) urban and suburban locations in the Boston Metropolitan area. There was

2 For one person, the age at first parole was unknown. 
little divergence among the group in socio-economic terms - most were unemployed at the time of the homicide or were working in manual jobs. The majority lived alone or with non-family members.

\subsection{Data Analyses}

The first interviews conducted for this study were exploratory in nature, and then increased in depth along the way - going deeper into certain aspects of the life course and delving into lifers' perspectives on what constituted successful and unsuccessful re-entry. A state of saturation was reached after about 40 interviews with both non-incarcerated and re-incarcerated lifers. The 24 interviews that followed served to crosscheck themes identified by the analyses.

Following content analysis techniques used in previous works [36,37], initial data analyses consisted of reading the text several times, and then noting connections, associations, and preliminary interpretations. Analytic conclusions were formulated by coding and then categorizing similar statements of experiences from data, replicating qualitative methodologies described in other studies on paroled offenders [36]. With the aid of qualitative software [38], these statements were grouped into categories and were then compared across all transcripts to identify connections, patterns, or contradictions.

\section{Results}

\subsection{What Types of Factors (Social, Institutional, and Personal) are Most Prevalent in Lifers'} Attributions to Success Post-Release?

In this section we will discuss our results as they pertain to social, personal, and institutional factors. It is important to note, of the non-incarcerated individuals, two-thirds remained crime-free after release, while seven were re-incarcerated for either criminal or technical violations. Because the average time since release for this group was nine years, we are able to say with confidence that the majority of non-incarcerated participants were indeed successful in staying out.

\subsubsection{Social Factors}

Interviewees did not strongly attribute success post-release to social factors. In some cases, social support was beneficial to their re-adjustment post-release, but in most others, we found evidence that social ties did not act as pro-social forces, but rather as negative influences. Our findings suggest that the extensive time spent behind bars was a significant issue here. When participants were released, many of them had deceased parents, and/or children who were adults, aunts, uncles, cousins, siblings, and intimate partners who had started new lives. Some participants also reported being too old to start a meaningful career. We will further address the roles of intimate partners, parenthood, family ties, and employment individually.

\section{Role of Intimate Partner}

Contrary to what we might expect based on the literature on short-term incarcerated offenders, none of the (incarcerated or non-incarcerated) interviewees referred to an intimate partner as a reason for (periods of) abstinence from criminal behavior. As can be seen in Table 2, the two groups did not 
clearly differ in terms of relationship status: One-third of the non-incarcerated interviewees were in a relationship, compared to half of the re-incarcerated interviewees. Approximately one-fourth of all interviewees described their relationship status as ambiguous, being somewhere in-between committed and non-committed.

Table 2. Employment status, relationship status and parenthood among released lifers post-release $(\mathrm{N}=68)$.

\begin{tabular}{|c|c|c|c|c|c|c|}
\hline \multirow[b]{2}{*}{ Employment } & \multicolumn{2}{|c|}{$\begin{array}{c}\text { Non-Incarcerated } \\
\text { interviewees } \\
(\mathrm{N}=\mathbf{2 8}) \\
\end{array}$} & \multicolumn{2}{|c|}{$\begin{array}{c}\text { Re-incarcerated } \\
\text { interviewees } \\
(\mathbf{N}=\mathbf{3 6}) \\
\end{array}$} & \multicolumn{2}{|c|}{$\begin{array}{c}\text { Total } \\
(\mathrm{N}=64) \\
\end{array}$} \\
\hline & $\mathrm{N}$ & $\%$ & $\mathrm{~N}$ & $\%$ & $\mathrm{~N}$ & $\%$ \\
\hline Unemployed, not in school & 5 & 17 & 3 & 8 & 8 & 13 \\
\hline Manual employment & 8 & 27 & 27 & 75 & 35 & 55 \\
\hline Counseling & 13 & 46 & 3 & 8 & 16 & 25 \\
\hline Other (in school, creative or white-collar job) & 2 & 7 & 3 & 8 & 5 & 8 \\
\hline \multicolumn{7}{|l|}{ Intimate partner } \\
\hline Married/In a committed relationship & 10 & 38 & 18 & 50 & 28 & 44 \\
\hline Ambiguous & 7 & 27 & 9 & 25 & 16 & 25 \\
\hline No intimate partner & 11 & 39 & 9 & 25 & 20 & 31 \\
\hline \multicolumn{7}{|l|}{ Parenthood } \\
\hline Children & 16 & 57 & 18 & 50 & 34 & 53 \\
\hline No children & 11 & 39 & 17 & 47 & 28 & 44 \\
\hline
\end{tabular}

The interviewees actually revealed several reasons not to become involved in intimate relationships after release. They prioritized their own recovery over involvement with an intimate partner. It should be noted that many programs for ex-offenders actively discourage such involvement for at least a year post-release:

The worst thing would be to get into a committed relationship that I knew I wasn't ready for $[\ldots]$ I think we need to grow into that. And part of that growth process is coming to terms with certain things about ourselves. I think in order to have a healthy relationship, with a partner, I think you really need to be [...] accepting of who you really are, not who you want to be.

(Non-incarcerated male, age 50)

Many who became involved in an intimate relationship soon after initial release typically referred to this as "playing catch-up", compensating as quickly as possible for "lost" time. Among this group, rather than intimate partner relationships acting as a potential deterrent, interviewees attributed failures of parole to circumstances involving their intimate partners. One of the interviewees, for example, had been sober for several months when he met a woman, and quickly moved in with her:

But she wasn't as grounded as I was. She was using and I felt confident in my sobriety. I was like: 'See, she is using, but I'm clean, I'm good, I'm strong.' And one day, I remember, she set a cigarette down in the ashtray and [...] before I knew it, I would go to the store, buy a pack for her and buy a pack for myself, too. And I would buy her a bottle 
and get two beers myself. So I was on a slippery slope. Before I knew it, I was smoking weed with her and started using alcohol.

(Re-incarcerated male, age 58)

Others attributed their re-incarceration indirectly to their companions, such as the following interviewee, who turned to unlawful means in order to give his girlfriend a lifestyle he couldn't afford in legitimate ways:

I think I tried to play catch-up. My girlfriend, you see, she was a stripper. And she earned a lotta cash for just working a couple of nights. Now, when she became pregnant I tried to keep on living her lifestyle, the lifestyle we had with her salary, but we couldn't [...]. So, the other side kicked in, that criminal side of me, when it wasn't supposed to.

(Re-incarcerated male, age 42)

Less than half of the total sample was married at the time of the interview. For the US population, the median age of first marriage is 29 [39]. The large majority of our sample was incarcerated at this age, and for many years after. Therefore, general delinquents who serve shorter sentences may have the opportunity to establish such relationships post-release, whereas this sample "misses the boat". We should also note that, in line with findings reported elsewhere [40] in contrast to a "typical" romantic relationship — which may be understood as consisting of two individuals - the relationships described by interviewees were often characterized by dynamic composition. The interviewees reported frequent changes in romantic relationships, having more than one intimate partner, and at times, children with more than one woman. In short, none of the successes, but rather some of the failures, were attributed to the role intimate partners played in their lives post-release. "Catching up" on lost time often proved to have a negative, rather than a positive outcome.

\section{Role of Parenthood}

In their narratives, none of the interviewees attributed their success post-release to the role they took on as a parent. Even though as reflected in Table 2, more than half of the men in the sample had children, the vast majority did not take on a parental role before, during, or after incarceration. They were incarcerated when their children were very young and by the time they were released, their children were adults. For the interviewees, parenthood occurred "off-time" relative to members of their age cohort who were not incarcerated, and thus parenthood lost its potential as a deterrent. The average US man fathers his first child in his mid-twenties [41]. Most participants, however, were incarcerated during their twenties and thirties - a potentially critical time for family formation, and were either fatherless, or had fathered a child at a very young age before they were incarcerated. For some, becoming a parent at a socially inappropriate age further solidified their already marginalized identities.

For the interviewed lifers, personal visits from their children were difficult to maintain during incarceration. This was due to the distance between the place of incarceration and the child's place of residence, the associated costs of travel, and most importantly, the willingness of mothers to facilitate visitation between incarcerated fathers and their children. None of the interviewees maintained relationships with the mothers of their children while incarcerated; hence, contact with their children became virtually nonexistent: 
Lots of things I wasn't privy to [...] things with my daughter [while in prison]. While we were living in the same house [after I got out], she felt uncomfortable, I felt uncomfortable [...] She had a lot of anger and resentment towards me. She would call me a 'telephone father.' [...] When I moved out to go and live with my girlfriend, she felt like I was abandoning her all over again.

(Re-incarcerated male, age 40)

Those who became fathers after they were released from prison indicated they had gone through a meaningful life transformation prior to meeting their intimate partner and having children. Others, who became involved with an intimate partner, described the presence of children and stepchildren as a complicating factor, rather than a positive one:

Now, the [step]-kids have seen my [ankle] bracelet. So now they think I'm a weirdo or something. I ain't telling them nothing about my life. It's none of their business, really. So, now the 14-year-old daughter is judging me, saying that I'm no good at this and that and that I should be in prison.

(Non-incarcerated male, age 52)

The majority of the interviewees who had children prior to going to prison were estranged from their children. The time in prison had created a distance between the interviewees and their children that could not be bridged:

This is good...neither of us are ready to have a relationship. I feel totally powerless with her. I can't help her. I'm forced to be in here [...] I'm seeing my life disappear [...] my home life is completely destroyed.

(Re-incarcerated male, age 40)

I distanced myself from them... My [three adult] sons, I cannot tell them what to do and how to do it. I just play it safe.

(Non-incarcerated male, age 59)

What both groups of lifers had in common, were the difficulties they faced in re-establishing relationships with their children post-release. After decades of incarceration, these children had become adults, hardly knowing their incarcerated parent. Again, rather than parenthood acting as a contributing factor post-release, parenthood most often acted as a stressor.

\section{Role of Family Ties}

We further asked the interviewees about the roles of family relations in their lives post-release. Many interviewees from both the incarcerated and non-incarcerated groups indicated that their parents, siblings, and extended family members died while they were incarcerated or passed away shortly after they were released. In most cases, visits from family members diminished over time. For others, family members did not act as pro-social role models in the desistance process. Many interviewees emphasized the absence of father figures in their childhood, adolescence, and later in life-fathers were incarcerated, or more commonly, had never been present in the interviewees' lives. Others pointed out that parents and siblings did not constitute a significant source of support because of drug 
use, incarceration, or involvement in crime. A small group of interviewees, who were still in contact with their family members, expressed that they needed to work hard to improve relationships with their families post-release. Not infrequently, the interviewees felt that family members had given up on them, and that they needed to prove to loved ones that they had redeemed themselves:

When I got out, I wanted my family to embrace me, to welcome me, to understand that I was gonna do the right thing and be a person that I now need to be, a healthy responsible person, and they weren't sure. They wanted to see it. People who you've hurt in the past, they want you to demonstrate that you're a changed person, long enough that they can rebuild and regain some trust. [It wasn't until] the second or the third year of doing the right thing and being out in society, my whole family started looking at me differently.

(Non-incarcerated male, age 45)

Now, this interviewee describes himself as a family man, engaged in every type of family activity, organizing get-togethers and acting as a father figure for his younger cousins. It takes time, though, he says. And hard work. This sentiment is shared by the following interviewee, who is in charge of a local job agency. As part of his job, he engages in public speaking for ex-prisoners. When he speaks to groups about the problems associated with re-entry, he always cautions his audience that they should not expect their families to receive them with open arms:

You know, expecting your family to believe that you're no longer that person that was taken out of their living room in handcuffs - is that really fair to do to your family? You've gotta convince them through hard work, and compassion and understanding where they're from. Obviously, if you're known to be violent and do you want. Do families necessarily want to bring you in amongst the kids in the family to adopt your moral beliefs until they know for sure that you are better and working hard?

(Non-incarcerated male, age 40)

Although most found it difficult to deal with family members, the interviewees did not express a common pattern in terms of how to deal with family relations after release. One of the interviewees, for example, pointed out that his family did not fully understand what he had been through. "You know, you just cannot, after fifteen or twenty years, maybe even after seven years, you cannot go back to your family. It is just too much", he insisted, "for them, and for you, because you are setting yourself up for a serious, serious mess. They are not equipped to deal with people who have been imprisoned for a long period of time."

Role of Employment

We investigated the role of employment in interviewees' ability to do well post-release. Interviewees in both groups emphasized that they only did well when they had jobs where they were considered valued employees. Furthermore, during times in which interviewees struggled with a steady income, they also struggled with "going straight":

The parents became aware that I was an ex-inmate and they did not feel competent knowing that I was an ex-inmate working with their children. The agency fired me and, 
that triggered off all that negativity because I could not understand or rationalize it. [...] I broke down and I went back into that mode where: "Okay you hurt me, I hurt you". Meaning, in my mind, I am saying: "I am trying to go straight and this is what I'm getting? So, let me do what I know", and I went back into the street mentality.

(Non-incarcerated male, age 63)

The reason why the relationship between employment and desistance was not straightforward is at least twofold: First, it can be traced back to the "off-time" occurrence of transitions into adult roles. Even though many interviewees reported that they had not gotten further in life, building careers, forming families, purchasing houses, and taking on other adult roles, others emphasized the sense of being behind schedule:

I am not getting any younger, I am transitioning into-I am 63 years old-I am transitioning into a career at a point in my life where most people my age would be retiring. I am just starting with a career! I need some time to start paying off these [student] loans and debt that I'm in from that.

(Non-incarcerated male, age 63)

Second, in line with findings reported in prior research $[12,41]$, both re-incarcerated individuals and those under parole supervision spoke about the prominence of the felon label when seeking employment. Employers were reluctant to hire them, largely due to the widespread use of CORI (Criminal Offender Record Information) checks. Interviewees typically worked in either construction jobs (union jobs that did not require CORI checks) or in counseling and advocacy positions in which they were able to use their criminal history to help others in a professional setting. In the meantime, interviewees had to get their employment approved by their parole officers, which increased the difficulty of finding a suitable job:

I [was] working for my brother, he's giving me $\$ 300$ cash a day [...] and they say: "You can't work for your brother." [...] This is what the parole guy says to me [...]. I got a job, the next day. [...], I go over and tell him I have a job over [...] at the scrap metal yard. He says: "Oh no, you're not working at the scrap metal yard. There's something wrong with it."

(Non-incarcerated male, age 52)

These difficulties inhibited the potential benefits of steady employment on desistance among this sample.

The relationship between employment and success post-release went further than being a mere "social factor" among those who used past experiences in their work as counselors in ex-offender programs or as paralegals for prisoners' rights organizations. These individuals had acquired legal skills while in prison, or had been heavily involved in post-prison programming to such an extent that they transformed from the "helped" into the "helper". We found that for these "professional exes" [7], doing this type of work was part of "making good"-or fulfilling a role of giving back that shows up as inherent in their newly found identity or self [7]. Approximately half of the non-incarcerated individuals had steady employment in a counselor-type position, versus eight percent of the re-incarcerated lifers. This type of meaningful employment could thus very well explain reasons for success post-release. Much like sober individuals in Alcoholics Anonymous [42], these generative 
activities may be therapeutic for ex-offenders, which in turn helps them maintain a conformist or desisting path post-release.

\subsubsection{Institutional Factors}

Interviewees typically first became involved in prison programs (including behavioral modification, vocational training, and college education) out of extrinsic motivation in order to increase their chances of being paroled. Through participation, however, many interviewees found that these programs functioned as a catalyst for change. This is in line with the "hook for change" notion reported by Giordano et al. [6]. After interviewees found a hook for change in the prison programs that they participated in, they personally became open to the positive influence of institutional programs:

My GED is what really kicked in into gear 'cause I scored pretty high on my GED [...] The more educated I got, the more I realized I could do things that were amazing that I didn't realize I could do. [...] The GED made me say, "Okay, I did this, I can do college too." [...] I started moving forward, and I started doing programs, and when I was doing programs, people began asking me to speak at the programs [...] I was only involved in the programs to get parole, I was not involved in the programs because I believed in them. Then I started looking at some of the stuff and going, "wait a minute, that's me, whoa."

(Non-incarcerated male, age 40)

Programming was equally available to both groups, and interviewees in both groups described that programs changed their "criminal way of thinking", taught them to see their "real selves", and discard their "old, criminal selves". Even though interviewees had engaged in violent behavior, they did not consider themselves to be violent people. They stressed that they had become involved in these activities due to environmental factors, such as pressure from a group, or growing up in an impoverished area where crime and drug use were rampant. Almost all interviewees emphasized that this was how they had behaved - but by the time they faced the Parole Board, they were changed: Prison programming enabled them to create a narrative in which they shed their old, delinquent selves and transformed into the person they were supposed to be all along. The majority of the men we interviewed described that they were now a different person as compared to who they were when first incarcerated. The central feature of their narratives was the use of past tense when referring to their "old self":

"If you ask some people to explain me back then [...] I've never done anything wrong to my friends, or my family, but if I didn't know you, I didn't care about you. It was 'I, I, I, I, I, I, I.' I had this warped sense of being that was just wrong."

(Non-incarcerated male, age 45)

While many described that prison programs contributed positively to their desire to change and leave their criminal past behind while they were incarcerated, very few interviewees believed that any vocational and educational programming that they had participated in prison contributed to their lives once they were released. They pointed out that many vocational and educational programs in prisons were designed for short-term inmates. As long-term inmates, they were oftentimes not eligible for programs geared towards re-entry: 
"They have nothing to offer here, only AA, NA, the CRA [Correctional Recovery Program] and Alternatives to Violence. But for all other programs, they give priority to people with the earliest release date. So I can sign up for GED classes, but won't get them until a year from now [...] It's me sitting here day in day out, reading books and watching TV. I ref (referee) basketball and softball games, and that's it."

(Re-incarcerated male, age 44)

After many years of incarceration, interviewees reported a potpourri of educational achievements, including an associate's degree in sociology, a barber's license, and plumbing and other vocational certificates. For the most part, however, prison did not give individuals new skills that they could use to launch a conventional career, with the exception of individuals who had been involved in the furlough program. Participants believed that this type of programming prepared them for life post-release:

Interviewee: [The furlough program] changed my life [...] because when I went in, I didn't really have any values. I was just doing time [...]. And I never really held a job or worked like that. It was good. They [his clients] did not know I was in prison.

ML: How did the program affect you, once you got out of prison?

Interviewee: It socializes you, because it was a work environment. I mean you're not just with other inmates [...]. You gotta learn how to answer the phone in a business-like way. And all this kind of thing, you know, I mean just real practical skills [...]. I mean, if I never went to the program, I would have never made it out. And I met a whole lot of people that have said that too. [...] The guys who went through the program, I sat most of them, stayed out. I think every one should've went through that program. Every lifer that was $[\ldots]$, phased out of the system, should've went through that program.

(Non-incarcerated male, age 66)

Furloughs were used extensively throughout the United States between 1950 and 1975, but were, for the most part, abolished due to an increasingly punitive penal climate. Many of the older interviewees had participated in the furlough program, but following the Willie Horton case in 1987, all furloughs were terminated in Massachusetts.

In terms of post-prison programming, there was a network of religious, community and re-entry organizations available. The majority of interviewed lifers from both groups reported to have voluntary contact with at least one of these organizations. Given the absence of established family ties, many of these organizations functioned as a main social network to rely on post-release. With regard to mandatory post-prison programming, most interviewees were required by parole to attend AA or NA meetings, as many had committed their crimes while under the influence of alcohol or drugs. Even though some lifers considered this type of programming helpful, the majority of interviewees expressed skepticism towards these programs:

"It didn't help me. People were there [at the AA meeting], getting high, coming in with brown bags. I mean, drug dealers came there to deal drugs. That is not helping anyone."

(Re-incarcerated male, age 52) 
"I went because I had to go, not because I wanted to go. I mean, they got high at those meetings. They were unsupervised. How can you respect those meetings when everyone's high?"

(Re-incarcerated male, age 51)

"Everyone was just sharing war stories, like 'Hey man, I was smoking dope and crack and all that...' I mean, there was nothing about change, or about fixing the problem."

(Re-incarcerated male, age 43)

In summary, with the exception of certain types of employment, we found limited influence for the influence of social relations and the influence of (post-prison) programming in post-release success versus failure. Lifers in neither group attributed their success post-release to social or institutional factors. This brings us to our second question.

\subsection{How do Non-Incarcerated and Re-Incarcerated Lifers Differ in How They Attribute Success to} These Various Factors?

\subsubsection{Self-Efficacy}

For the most part, interviewees attributed their success post-release largely to their own self-efficacy. Those who were successful on parole, opposed to those who had been re-incarcerated, emphasized that they saw themselves as active agents in their own lives. Contrary to the re-incarcerated group, non-incarcerated participants reflected a strong sense of agency in their narrative: Two-thirds of this group of lifers emphasized that they were able to stay out because they took control over their lives after release. Consider, for example, the following interviewee, who obtained a paralegal degree shortly after his release:

"I felt, you know, that there was nothing that was not possible, that, I felt that, you know it was almost like a redemption, it was, it was like if you actually sincerely try to do good and tried [...] there will be many as believers, many naysayers, people thinking you are running a scam, a con, or whatever, right? And you suffer setbacks, you will get punished for this and that, but if you stick with it, ultimately, having faith in people, you will prevail. And, so that was, that [obtaining a paralegal degree] was proof of that."

(Non-incarcerated male, age 65)

Similarly, the following interviewee expressed a strong degree of self-efficacy, reflected by his clear vision for, and his sense of control over the future from the day he was released:

"First thing I did after being released from prison was go around the corner and I got a double quarter pounder. I went to McDonald's. So then I went to parole, I had to come back, I said: 'Well let's go get my permit.' They're like: 'What?' I said: 'Let's go get my permit', cause I made sure I had all of my stuff so I could get my driver's license; I did all this before I got out. [...] In four hours I got my learners permit to drive. I hear that nobody's ever done that before either. I believe that's not true, I think people have they just don't tell people how to do it-I share the information with people. So I got my learners permit and I drove back to parole. And I went into parole and I showed 'em my learner's 
permit, they laughed, they were like: 'You got your learner's permit already?' I was like 'yeah, I had to wait to see you so I went over and got my learner's permit.' Five days later I have my license and I had my own car. And I told everybody before I left prison, I said that within two to three years, I will own my own home, and I'll make it. [And they said:] 'Right'. Watch me [...] And if you think about it, I started here [two years ago] so if you think about it, I started this job making about 35 grand a year, six months after I got out. Then, two years to the day of my release, I got approved to buy my home."

(Non-incarcerated male, age 40)

These narratives stand in stark contrast to roughly three-fourths (20 out of 28 , or $71 \%$ ) of the narratives of re-incarcerated lifers, who mostly attributed their failure to external factors. "What do you think the main reason is for you and others to return to prison?" We asked one of the re-incarcerated interviewees. "Hanging with a bad crowd will bring you back. Hanging with a good crowd will save you. You have to stay with the right people, like AA people."

Another example includes the following 52-year-old man, who stayed out for almost 14 years before re-incarcerated. He ascribes his re-incarceration to the economic downfall:

"I was making \$35 an hour, I had two vehicles, but the economy started going bad. I lost the job, my wife started to have migraines because of that, I had surgery and I started paying with credit cards. I couldn't find a job and I was starting to get depressed."

(Re-incarcerated male, age 52)

Such external attributions to success ("someone to lean on"; "a good crowd") and external attributions to failure ("it was the economy"; "a bad crowd") were very common among those who were re-incarcerated. Non-incarcerated lifers expressed a strong sense of self-efficacy. This stands in contrast to those in the re-incarcerated group, who felt they had no, or hardly any, control over their lives. Among the re-incarcerated group, expressions, such as "my fate is in the hands of my Parole Officer", and "they did not tell me I had to find employment", "there was no-one I could rely on", "it's just another prison out there", were common. The lack of self-efficacy among many of the interviewees who were re-incarcerated was further expressed by their view that their lives were largely controlled by external factors:

And that's where I went wrong. I forgot I was on parole. Life was getting comfortable.

And then one day, a guy at work saw that I was in pain [from a recent knee operation] and gave me some valium. And I tested positive and went back in.

(Re-incarcerated male, age 58)

Voluntary, or "agentic" action can, in principle, be modified by the actor on request [43]. However, this ability has been deeply suppressed by the interviewees' many years in prison. Those who were successful in staying out of trouble with the law were able to re-build this sense of agency after many years of confinement, while those who were re-incarcerated did not seem to have re-acquired this sense of agency to the same extent. 
False Positives and False Negatives

The dichotomous division of agentic (non-incarcerated) versus non-agentic (re-incarcerated) lifers is not complete without considering cases that did not neatly fit this division. Out of the total 38 re-incarcerated interviewees, 10 individuals reflected a strong sense of self-efficacy in their narratives, but were nevertheless considered "unsuccessful" due to their re-incarcerated status. Consider the following interviewee, for example, who was sent back to prison for a technical violation: When his Parole Officer showed up at his house, he was at his brother's house without notification. He describes that, in his 17 years in prison he, “...decided to change, and it wasn't handed to me on a silver platter. I had to do the work." Throughout the interview, he emphasizes that: "There is always a choice." Even in prison, he says:

"I can choose not to eat. I can choose not to wear this monkey suit [pointing to his jumpsuit]. They can say what they want, but I have a choice. I don't have to listen to him [pointing to the Correctional Officer in the adjacent office]. You will be sent to the hole [solitary confinement] for that, but it's a choice. I won't let them take away my freedom, my choice, my individuality, even if I'm wearing this suit like a monkey, I'm still who I am."

(Re-incarcerated male, age 41)

Conversely, there were a total of eight non-incarcerated lifers, who presented a low degree of self-efficacy. Consider the following 42-year-old interviewee, for example, who admits to using and selling drugs on a regular basis ever since he was paroled two years ago, but downplays its significance:

“But I wasn't [doing anything else] but selling some drugs, and even when I did, and I sold drugs since I've been home, but I'd [only] sell to five people [as opposed to many more]."

When asked how he was successful in staying out on parole, he simply said: "I don't wanna go back to prison." One-third of participants in the non-incarcerated group lacked a strong sense of self-efficacy, but were still successful in staying out. This can largely be attributed to luck of circumstances - parole violations going undetected or staying under the radar due to a more reclusive lifestyle or personality.

\section{Discussion}

This study is the first to assess the extent to which individuals who served a long prison term attribute three different clusters of factors, both individually and also combined, to their success in staying out of prison post-release. Now that we have addressed how lifers who were successful in staying out differ from lifers who are re-incarcerated in how they attribute success to these various factors, we conclude with a discussion of our final question.

\subsection{How Do These Results Indicate How Lifers May Differ from Short-Term Offenders?}

Previous research in life-course criminology has shown how desistance from crime is linked to the successful transition to adult roles, in particular a strong marriage and stable employment [11,12,14,16,44].

First, from the perspective of life-course research, establishing and maintaining an intimate relationship constitutes a "stake in conformity" [16], as the attachment to an intimate partner serves as 
a powerful motive to desist from crime, because of fear of hurting or jeopardizing relationships [45]. The findings of this study, however, show that lifers rarely indicated intimate partners as a positive influence. Participants in neither groups had pro-social factors working for them: Few of the lifers in the, non-incarcerated group were engaged in relationships, and to the extent that they were, they emphasized having first experienced a cognitive shift before becoming involved. Many actively discouraged other fellow ex-inmates from seeking an intimate partner. Numerous re-incarcerated lifers, in contrast, were re-incarcerated as a result of negative aspects of their intimate relationship. The partner they had become involved with did not provide a stake in conformity, but rather encouraged behaviors that resulted in re-incarceration. Many of these failed relationships can be traced back to the interviewees' desire to fulfill a pro-social role. Arguably, the desire to "catch up" with what they missed during their many years in prison made them uncritical in their choice of intimate partnermany started relationships with partners who suffered from poor physical and/or mental health, including suicidal behaviors, drug and alcohol abuse, and criminal behaviors.

A second life-course element that was prevalent in previous research, but not in the study at hand, is the role of parenthood post-release. Those who became a parent prior to incarceration - both those who were successful in staying out of prison and those who were re-incarcerated-were significantly "off-time" in becoming a parent. Those who had children typically became fathers in their teenage years, which - due to their age at the time of conception and birth of their child(ren) — did not contribute to desistance, but rather contributed to their already marginal socio-economic status. A third element, based on recent life-course research, constitutes pre-existing family ties, which are thought to contribute positively to success post-release. Even though prior research has found a strong relationship between family contact during incarceration and desistance [8,17], the lifers in this study sample did not attribute their success to these relationships. Change did not emerge out of a context in which the participant felt a moral duty to change as a compensation for family support they had received during incarceration. Rather, the interviewees hardly received family support throughout their incarceration or upon release, and encouragement from family members was not pronounced. Instead, reintegration into family life posed obstacles for these released lifers, as they were separated from family members for extended periods of time - a finding reported in other qualitative studies [12]. To the extent that family members were alive upon their release, and willing to engage in contact, respondents indicated that they felt they had to 'prove' themselves to their family members-to demonstrate that they were truly changed.

Rather than the role of intimate partners, parenthood, and pre-existing family ties having a strong impact on their success post-release, interviewees emphasized that steady employment played a major role in their success. The influence of this factor was particularly pronounced when the individual was able to find meaningful employment, in which they could use their narrative (e.g., working as a "professional ex", such as counselor or paralegal) as opposed to work that only paid the bills (e.g., warehouse employee or metal worker). Employment was a contributing factor in success post-release, but not as strong as we may have expected from the literature. This could be explained by the phenomenon that after release, the effort to secure a conformist identity was undermined by the stigma of a felony conviction. This challenged participants' efforts to establish a commitment to pro-social roles-an observation also encountered in Uggen et al.'s [12] qualitative work on stigma and reintegration. One may argue that if these individuals were truly efficacious, they could use their 
agency to overcome structural limitations imposed by criminal background checks and limited access to the labor market. However, it is vital to note that ex-offenders face an uphill battle to career employment, compared to individuals who do not have a criminal history.

Most prominent in interviewees' narratives of post-release success, was the notion of personal efficacy. In their narratives, they highlighted the importance of self-efficacy, more so than social factors, in making the transition from a life of offending behavior to a conventional life. In order to be successful post-release, individuals needed to shed their old identity and be able to construct a pro-social self that contradicted their past lifestyle. Even though interviewees in both the non-incarcerated group and re-incarcerated group presented a narrative in which they distanced themselves from their old identity, high levels of self-efficacy were predominant among those who were successful in staying out - this group voiced the ability to overcome circumstances that contributed to past and future offending. In addition, they expressed a high degree of self-efficacy in having a clear perspective of the future in which they took an active, rather than passive, role. It is important to note that while the non-incarcerated sample did express higher levels of self-efficacy, nearly one-third of this group did not do so. This can largely be attributed to circumstances of certain behaviors going undetected. Further, the majority of the re-incarcerated group entirely lacked any self-efficacious language. From a critical point of view, the lack of self-efficacy among re-incarcerated lifers could be a reflection of their current state of incarceration. While constructing their narratives, re-incarcerated interviewees may downplay the ability to exert control over the structural disadvantages facing them and emphasize the influence of other factors, whereas non-incarcerated interviewees may do the opposite. Similarly, it may be argued that self-efficacy flourished in a context of various social factors that were present for non-incarcerated interviewees, and absent for re-incarcerated interviewees. However, as the results indicate, both groups of lifers seemed to be "off-time" in terms of traditional turning points in the life course: The majority of participants were either single, or involved in problematic, rather than supportive, intimate partner relationships. In terms of other loved ones, over time, for both groups, visits from family members diminished. Interviewees lost contact with their children during their decades-long incarceration, or had never had the opportunity to have children. Interviewees in both groups struggled with securing and sustaining employment, and both groups had similar access to social support networks, such as religious institutions or substance-related programs.

Based on these findings, one may therefore argue that self-efficacy, or a lack thereof, may be a determining factor in explaining why some lifers are able to stay out post-release, while others return to prison. According to the view presented here, the process of staying out for lifers is not the result of coming-of-age societal forces (e.g., parenthood, marriage, employment) [46], as previously emphasized by life-course theorists $[8,9,11,14,16,24,28,45,47]$, but rather a change in the self, or a transformation of identity. Interviews with these lifers show that the group who was able to stay out reflected a strong sense of self-efficacy, while those who were re-incarcerated lacked this sense of voluntary action.

Finally, the interviews revealed that institutional factors - in this case, the availability of (post-)prison programs - positively influenced interviewees. Even though prison programs and post-prison programs contributed to their likelihood to do well, and in some cases acted as a catalyst for change, interviewees emphasized that they were still "self-changers". Maruna, Immarigeon and LeBel [48] pointed out that individuals spend only a tiny fraction of their daily lives participating in programs, so most of the hard work involved in changing their sense of self takes place outside of these programs. The interviewees 
reiterated the truism that, at the end of the day, "you have to do the work". Our findings emphasize the intertwined relationship between personal and institutional factors: Many lifers reported having experienced a cognitive shift through their exposure to prison programs, or, conversely, participating in prison programs after having made the decision to change - a finding also reported elsewhere [13]. This corresponds to Giordano et al.'s [6] notion of "hooks for change": The individual finds a catalyst in prison programs that leads him to consider replacing his "old self" with a "new self". In addition, non-incarcerated (successful) interviewees emphasized the role of re-entry programs in making them aware of their own potential — thereby strengthening their personal efficacy.

\subsection{Implications for Policy and Practice}

Re-entry is a long-term process, one that actually starts prior to release and continues well afterwards [48]. In line with findings from prior research [8,11], this study emphasizes the critical role of employment in the construction of a narrative of desistance, and in particular in the perception of self-efficacy. It would be beneficial for states to implement policies and develop programs that encourage released inmates to obtain meaningful employment. This involves reconsidering the way in which background checks are currently applied; continuously applying the felon label in years well after release inhibits ex-offenders from obtaining meaningful employment and desistance from future crime $[12,49]$.

Released prisoners face multiple challenges when they return home, including substance abuse, (mental) health problems, legal issues, and housing. For released lifers, relationships with pro-social others (intimate partner, children, and other family members) either ceased to exist during incarceration, or was not rebuilt post-release. In their lives, re-entry and community organizations became imperative as a network to assist them in facing these challenges. The results of this study emphasize the importance of such organizations in the desistance process - in particular when programs can restore and strengthen participants' sense of agency.

\subsection{Strengths, Limitations, and Directions for Future Research}

Our analysis was designed to assess the factors contributing to post-release success among released lifers, rather than to provide a critical test of competing hypotheses. Other studies on desistance among lifers have relied on heterogeneous samples of individuals incarcerated for various reasons, and typically for shorter periods of time [36,50]. In our study, we employed strict inclusion criteria, focusing on lifers who were incarcerated for a homicide, thereby increasing the internal validity of our study. Previous studies on narratives of desistance among incarcerated offenders (e.g., [8,12]) were not able to assess to what extent those with a narrative of desistance were in fact desisting after release. We were able to overcome this limitation by including a relatively long follow-up period after release. In that way, we were able to provide evidence that the participants with a narrative of desistance were, for the most part, successful in staying out.

We should note that the resources available for Massachusetts' lifers may not be highly representative of the U.S. ex-lifer population. In Massachusetts, there are a variety of post-release programs available, which may not be equally available in other states. In addition, many of the released lifers in this sample were incarcerated in the late 1970s and early 1980s, and were able to 
benefit from in-prison college and furlough programs. The widespread availability of these programs has drastically diminished in recent years - this may limit the generalizability of our findings to recently released individuals. We have also emphasized a general threefold model of success post-release without attention to potentially important subgroup differences. For example, as Uggen et al. [12] suggested, it is possible that criminal history, race, and gender of the interviewees may condition the influence of the various factors we describe. Arguably, this also includes age at the time of incarceration. It has been suggested that those who were juveniles at the time of their sentencing may be more "changeable" than those who were engaged in a criminal lifestyle well into adulthood. Future research, with larger sample sizes to increase inferential power, should shed light on the differences in desistance processes between juvenile and adult lifers. Similarly, future work should assess differences in post-release success for male lifers compared to female lifers. Critical criminologists have long noted that female offenders are not supported in the same ways by social relations, and that relationships can actually lead to more crime rather than desistance [6,51-53]. Future research on these relationships among female lifers, and the nature (rather than only its presence) of these relationships to post-release success, is warranted.

Further, our study does not include lifers who are still serving life sentences without the possibility of parole (LWOP). Currently, approximately half of the prison lifer population in Massachusetts, or 1000 individuals, is serving an LWOP sentence [54]. We do not know how these factors (social, personal, and institutional) influence the lives of those who remain incarcerated. This may be particularly true when it comes to the influence of in-prison programming: Since these individuals are not eligible for parole, they may have different motivations to engage in prison programs compared to lifers who are motivated by the opportunity of parole. The same accounts for lifers who are still serving a life sentence with the possibility of parole, but who have not met the criteria set by the Parole Board. An important remaining question for research and policy concerning how lifers with the possibility of parole who have not yet met the criteria set by the Parole Board may differ in their level of efficacy from the paroled offenders in our sample. One may hypothesize that only those who are able to walk the fine line between "too much" and "too little" agency are eventually granted parole, and hence included in our study. In the first scenario, too much self-determination makes for an "unruly" prisoner: A prisoner who may take too much initiative in influencing his situation by, for example, questioning decisions by the administration and, as a consequence, receiving disciplinary reports that may ultimately result in a rejection from the Parole Board. Sykes (1958) points out that in prison, personal autonomy is taken away from the prisoner in areas of life, such as "the language used in a letter, the hours of sleeping and eating, or the route to work [...]" ([55], p. 290). Therefore, in the prison setting, the finality of authoritarian decisions demands a specified course of conduct in which there is no place for prisoners with too much agency. For decades, lifers have been subjected to a vast body of rules and commands designed to control their behavior in prison. One may speculate that enduring this loss of autonomy eventually leads to a profound lack of personal efficacy, creating a prisoner who lacks the agency necessary to be granted parole. Future research should attempt to shed light on this potential selection effect, for example by broadening the analysis to those lifers who are eligible for parole, but have never been paroled. 


\section{Conclusions}

Contrary to previous life-course research that has emphasized sociogenic forces in the desistance process (e.g., [8,9]), our findings indicate that identity change and desistance for long-term incarcerated offenders is intra-individual, rather than a socially supported process. The limited influence of social factors - compared to self-efficacy and institutional factors - may be explained by the "off-time" occurrence of potential social deterrents (marriage and parenthood), a profound absence of pro-social relations (intimate partner and family ties), and the presence of non-social relations (intimate partner) after release.

\section{Acknowledgements}

This research was supported by a Marie Curie Intra European Fellowship for Career Development in the project 299875.

\section{Author Contributions}

Marieke Liem was responsible for the study design, data collection, data analysis and writing of the paper. Jennifer Garcin contributed in data collection and writing.

\section{Conflicts of Interest}

The authors declare no conflict of interest.

\section{References}

1. U.S. Department of Justice. Prisoners in 2010. Washington, DC: U.S. Department of Justice, 2011.

2. Petersilia, Joan. When Prisoners Come Home: Parole and Prisoner Reentry. Oxford, UK: Oxford University Press, 2003.

3. Langan, Patrick A., and David J. Levin. "Recidivism of prisoners released in 1994." Federal Sentencing Reporter 15 (2002): 58-65.

4. LeBel, Thomas P., and Shadd Maruna. "Life on the Outside: Transitioning from Prison to the Community." In The Oxford Handbook of Sentencing and Corrections. Edited by Joan Petersilia and Kevin R. Reitz. New York: Oxford University Press, 2012, pp. 657-83.

5. Mauer, Mark, Ryan S. King, and Malcolm C. Young. The Meaning of "Life": Long Prison Sentences in Context. Washington, DC: The Sentencing Project, 2004.

6. Giordano, Peggy, Stephen A. Cernkovic, and Jennifer L. Rudolph. "Gender, Crime, and Desistance: Toward a Theory of Cognitive Transformation.” American Journal of Sociology 107 (2002): 990-1064.

7. Maruna, Shadd. Making Good: How Ex-Convicts Reform and Rebuild Their Lives. Washington, DC: American Psychological Association, 2001.

8. Cid, José, and Joel Martí. "Turning points and returning points: Understanding the role of family ties in the process of desistance." European Journal of Criminology 6 (2012): 603-20. 
9. Sampson, Robert J., and John H. Laub. "Life-course desisters? Trajectories of Crime among Delinquent Boys Followed to Age 70." Criminology 41 (2003): 301-40.

10. Farrington, David P., Bernard Gallagher, Lynda Morley, Raymond J. St Ledger, and Donald J. West. "Unemployment, School Leaving and Crime." British Journal of Criminology 26 (1986): 335-56.

11. Uggen, Christopher. "Work as a turning point in the life course of criminals: A duration model of age, employment, and recidivism." American Sociological Review 65 (2000): 529-46.

12. Uggen, Christopher, Jeff Manza, and Angela Behrens. "Less than the average citizen: Stigma, role transition, and the civic reintegration of convicted felons." In After Crime and Punishment: Pathways to Offender Reintegration. Edtied by Shadd Maruna and Russell Immarigeon. Portland: Willan Publishing, 2004, pp. 258-90.

13. Stevens, Alisa. "I am the person now I was always meant to be': Identity reconstruction and narrative reframing in therapeutic community prisons." Criminology and Criminal Justice 5 (2012): 527-47.

14. Laub, John H., and Robert J. Sampson. Shared Beginnings, Divergent Lives: Delinquent Boys to Age 70. Cambridge, MA: Harvard University Press, 2003.

15. Sampson, Robert J., and John H. Laub. "A General Age-Graded Theory of Crime: Lessons Learned and the Future of Life-Course Criminology." In Integrated Developmental and Life Course Theories of Offending. Edited by David Farrington. New Brunswick: Transaction Publishers, 2005, vol. 13.

16. Sampson, Robert J., and John H. Laub. Crime in the Making: Pathways and Turning Points through Life. Cambridge, MA: Harvard University Press, 1993.

17. Visher, Christy A. "Incarcerated fathers: Pathways from prison to home." Criminal Justice Policy Review 24 (2013): 9-26.

18. Horney, Julie, D. Wayne Osgood, and Ineke Haen Marshall. "Criminal careers in the short-term: Intra-individual variability in crime and its relation to local life circumstances." American Sociological Review 60 (1995): 655-73.

19. Lipsey, Mark W. "What do we learn from 400 research studies on the effectiveness of treatment with juvenile delinquents?” In What Works: Reducing Reoffending. Guidelines from Research and Practice. Edited by James McGuire. Chichester: John Wiley \& Sons, 1995.

20. Dowden, Craig, and Donald A. Andrews. "Effective correctional treatment and violent reoffending: A meta-analysis." Canadian Journal of Criminology 42 (2000): 449-67.

21. Wright, Kevin A., Travis C. Pratt, Christoper T. Lowenkamp, and Edward J. Latessa. "The Systemic Model of Crime and Institutional Efficacy: An Analysis of the Social Context of Offender Reintegration." International Journal of Offender Therapy and Comparative Criminology 57 (2013): 92-111.

22. Bandura, Albert. "Self-efficacy: Toward a unifying theory of behavioral change." Psychological Review 84 (1977): 191-215.

23. Bandura, Albert. "Human agency in social cognitive theory." American Psychologist 44 (1989): 1175-84.

24. Lopoo, Leonard M., and Bruce Western. "Incarceration and the formation and stability of marital unions.” Journal of Marriage and Family 67 (2005): 721-34. 
25. Pager, Devah. "The Mark of a Criminal Record.” American Journal of Sociology 108 (2003): 937-75.

26. Western, Bruce. Punishment and Inequality in America. New York: Russell Sage Foundation, 2006.

27. Western, Bruce, and Katherine Beckett. "How Unregulated Is the US Labor Market? The Penal System as a Labor Market Institution 1.” American Journal of Sociology 104 (1999): 1030-60.

28. Sampson, Robert J., John H. Laub, and Christopher Wimer. "Does Marriage Reduce Crime? A Counterfactual Approach to Within-Individual Causal Effects.” Criminology 44 (2006): 465-508.

29. Liem, Marieke. "Homicide offender recidivism: A review of the literature." Aggression and Violent Behavior 18 (2013): 19-25.

30. Liem, Marieke, and Maarten Kunst. "Is there a recognizable post-incarceration syndrome among released 'lifers'?" International Journal of Law and Psychiatry 36 (2013): 333-37.

31. Liem, Marieke, and Nicholas J. Richardson. "The Role of Transformation Narratives in Desistance among Released Lifers." Criminal Justice and Behavior 41 (2014): 692-712.

32. Liem, Marieke, Margaret A. Zahn, and Lisa Tichavsky. "Criminal recidivism among homicide offenders." Journal of Interpersonal Violence 29 (2014): 2630-51.

33. Unkovic, Charles M., and Jospeph L. Albini. "The Lifer Speaks for Himself: An Analysis of the Assumed Homogeneity of Life-Termers." Crime \& Delinquency 15 (1969): 156-61.

34. Massachusetts Department of Correction. "Block Brief: Offenders with Life Sentences." 2005. Available online: http://www.mass.gov/eopss/docs/doc/research-reports/briefs-stats-bulletins/ offenders-with-lifer-sentences-2.pdf (accessed on 5 December 2014).

35. Brooks, Lisa E., Amy L. Solomon, Sinead Keegan, Rhiana Kohl, and Lori Lahue. "Prisoner Reentry in Massachusetts.” 2005. Available online: http://www.urban.org/uploadedPDF/ 411167_Prisoner_Reentry_MA.pdf (accessed on 5 December 2014).

36. Appleton, Catherine A. Life after Life Imprisonment. Oxford: Oxford University Press, 2010.

37. Giordano, Peggy, Monica A. Longmore, Ryan D. Schroeder, and Patrick M. Seffrin. "A Life-Course Perspective on Spirituality and Desistance from Crime." Criminology 46 (2008): 99-132.

38. NVivo Qualitative Data Analysis Software. Version 10. Burlington: QSR International, 2012.

39. U.S. Census Bureau. Median Age at First Marriage. Washington, DC: U.S. Census Bureau, 2011.

40. Eddy, Bruce A., Melissa J. Powell, Margaret H. Szubka, Maura L. McCool, and Susan Kuntz. "Challenges in research with incarcerated parents and importance in violence prevention." American Journal of Preventive Medicine 20 (2001): 56-62.

41. Richards, Stephen C., and Richard S. Jones. "Beating the perpetual incarceration machine: Overcoming structural impediments to re-entry." In After Crime and Punishment: Pathways to Offender Reintegration. Edited by Shadd Maruna and Russell Immarigeon. Portland: Willan Publishing, 2004, pp. 201-31.

42. Marsh, Brendan. "Narrating Desistance: Identity Change and the 12-Step Script." Irish Probation Journal 8 (2011): 49-68.

43. Bottoms, Anthony. "Desistance, social bonds, and human agency: A theoretical exploration." In The Explanation of Crime: Context, Mechanisms, and Development. Cambridge, UK: Cambridge University Press, 2006, pp. 243-90.

44. Massoglia, Michael, and Christopher Uggen. "Settling down and aging out: Toward an interactionist theory of desistance and the transition to adulthood." American Journal of Sociology 116 (2010): 543-82. 
45. Ganem, Natasha M., and Robert Agnew. "Parenthood and adult criminal offending: The importance of relationship quality." Journal of Criminal Justice 35 (2007): 630-43.

46. Carlsson, Christoffer. "Masculinities, persistence, and desistance." Criminology 51 (2013): 661-93.

47. Bersani, Bianca E., John H. Laub, and Paul Nieuwbeerta. "Marriage and desistance from crime in the Netherlands: Do gender and socio-historical context matter?" Journal of Quantitative Criminology 25 (2009): 3-24.

48. Maruna, Shadd, Russell Immarigeon, and Thomas P. LeBel. "Ex-offender reintegration: Theory and practice." In After Crime and Punishment: Pathways to Offender Reintegration. Edited by Shadd Maruna and Russell Immarigeon. Portland: Willan Publishing, 2004, pp. 3-26.

49. Lee, Dara. "The Digital Scarlet Letter: The Effect of Online Criminal Records on Crime and Recidivism." Paper presented at the NBER Economics of Crime Working Group, Cambridge, MA, USA, 9-27 July 2012.

50. Dudeck, Manuela, Kirstin Drenkhahn, Carsten Spitzer, Sven Barnow, Daniel Kopp, Phillipp Kuwert, Harald J. Freyberger, and Frieder Dünkel. "Traumatization and mental distress in long-term prisoners in Europe.” Punishment \& Society 13 (2011): 403-23.

51. Daly, Kathleen. "Women's Pathways to Felony Court: Feminist Theories of Lawbreaking and Problems of Representation." Review of Law and Women's Studies 2 (1992): 11-52.

52. Daly, Kathleen, and Meda Chesney-Lind. "Feminism and criminology." Justice Quarterly 5 (1988): 497-538.

53. Salisbury, Emily J., and Patricia Van Voorhis. "Gendered Pathways A Quantitative Investigation of Women Probationers' Paths to Incarceration." Criminal Justice and Behavior 36 (2009): 541-66.

54. Andersen, Shawna. "Parole Decision-Making and Re-entry." Paper presented at the Annual Meeting of American Society of Criminology, San Francisco, CA, USA, 19-22 November 2014.

55. Sykes, Gresham. The Society of Captives: A Study of a Maximum Security Prison. Princeton: Princeton University Press, 1958, pp. 63-78.

(C) 2014 by the authors; licensee MDPI, Basel, Switzerland. This article is an open access article distributed under the terms and conditions of the Creative Commons Attribution license (http://creativecommons.org/licenses/by/4.0/). 